\title{
An automated method to quantify crop height and calibrate satellite-derived biomass using hypertemporal lidar
}

\author{
Jan U.H. Eitel ${ }^{\mathrm{a}, \mathrm{b}^{*}}$, Troy S. Magney ${ }^{\mathrm{c}}$, Lee A. Vierling ${ }^{\mathrm{a}, \mathrm{b}}$, Heather E. Greaves ${ }^{\mathrm{a}}$, Guang Zheng ${ }^{\mathrm{d}}$
}

\begin{abstract}
Crop biomass information is of great importance for a variety of applications, ranging from supporting farm management decisions to modeling the crop-environment system. Dimensionless spectral vegetation index values derived from satellite imagery are commonly used to derive crop biomass. However, the highly empirical nature of spectrally derived biomass estimates requires frequent and costly calibration with manually collected ground data. Recently, low cost, autonomously operating terrestrial laser scanners (ATLSs) have become available for near-surface applications. In contrast to the dimensionless nature of spectral index values, autonomous light detection and ranging (lidar) technology measures physical vegetation structure by recording the $\mathrm{x}, \mathrm{y}, \mathrm{z}$ coordinates of canopy components at very high
\end{abstract}


spatial $(<10 \mathrm{~cm})$, and temporal $(<2$ days $)$ resolution. The objective of this study was to assess the

suitability of an ATLS to i) monitor crop growth dynamics and ii) calibrate satellite imagery for estimating crop biomass. Wheat (Triticum aestivum spp.) growth was monitored by acquiring hypertemporal (every 28 hours for a full growing season) ATLS data at three different field sites across a range of experimentally manipulated crop growth conditions. The ATLS-derived crop height explained nearly three-quarters of the variability in destructively sampled wheat biomass $\left(r^{2}=0.74, \mathrm{RMSE}=514.20\right.$ $\mathrm{kg} \mathrm{ha}^{-1}$ ), showing a slightly stronger correlation to crop biomass than did leaf area index (LAI) measurements collected in the field using a LAI-2000 Plant Canopy Analyzer $\left(\mathrm{r}^{2}=0.71, \mathrm{RMSE}=546 \mathrm{~kg}\right.$ $\mathrm{ha}^{-1}$ ). Satellite-based crop biomass estimates calibrated with ATLS data captured the variability in wheat biomass throughout a farm field with a biomass error of 730.96 and $727.60 \mathrm{~kg} \mathrm{ha}^{-1}$ (RMSE) during the jointing (Development stage: Zadoks 37) and heading (Development stage: Zadoks 50) growth stages, respectively. These findings suggest that the hypertemporal lidar information provided via ATLS technology could constitute a major step forward in operational monitoring and mapping of crop biomass.

Keywords: Autonomously operating terrestrial laser scanner (ATLS), Leaf area index (LAI), hypertemporal lidar, crop biomass, biomass scaling, error accounting, laser allometry

\section{Introduction}

Crop biomass information is of great importance for a variety of applications ranging from environmental modeling to supporting farm-based forecasting and management decisions. However, it remains difficult to obtain accurate and standardized information about crop biomass at the field to landscape scale due to a lack of automated and cost-effective technologies designed for such a purpose. Instead, crop biomass estimates still commonly rely on time- and cost-intensive manual ground measurements such as destructive biomass sampling or non-destructive optically based measurements of leaf area index (LAI) using optical devices (Norman and Campbell, 1989). In an attempt to more 
efficiently estimate crop biomass information at the field scale and beyond, remote sensing approaches are commonly employed. Many of these remote sensing approaches rely on dimensionless spectral

50

51

52

53

54

55

56

57

58

59

60

61

62

63

64

65

66

67

68

69

70

71

72

73

vegetation indices calculated using mathematical combinations of reflectance data in different wavebands (e.g., Bannari et al., 1995). To convert these dimensionless spectral index values into meaningful physical biomass metrics, simple calibration equations are commonly established between ground-measured biomass and the spectral indices (e.g., Nguy-Robertson et al., 2014). Though relatively easy to derive, such approaches rely on manual ground sampling and highly empirical calibration equations. However, spectral indices are not only affected by variations in biomass but by a multitude of other factors such as foliar biochemistry (e.g., foliar water and chlorophyll concentration), soil background, viewing and illumination geometry, and canopy architecture (Jasquemoud and Baret, 1990; Verhoef, 1984; Jackson and Huete, 1991; Eitel et al., 2009). Consequently, spectral index to biomass relationships are limited in their spatial and temporal transferability and require frequent and costly recalibration (Baret and Guyot, 1991; Verstraete et al., 1996; Foody et al., 2003; Vuolo et al., 2013). A less empirical approach that does not require costly ground sampling relies on the inversion of radiative transfer models (e.g., Haboudane et al., 2002; Eitel et al., 2007). However, several challenges limit the use of the radiative transfer based inversion approaches, including uncertainties in the model and reflectance measurements, violation of radiative transfer model assumptions, and the ill-posed problem where different model parameterizations result in similar spectra (Combal et al., 2002; Atzberger, 2004).

A viable alternative to passive remote sensing-based crop biomass estimates is the use of light detection and ranging (lidar) (Ehlert et al., 2009; Long and McCallum, 2013; Eitel et al., 2014; Hoffmeister et al., 2015). This laser-based technology provides physical biomass proxies such as plant height and has been successfully used for mapping biomass in many ecosystems, ranging from the Arctic (e.g., Greaves et al., 2015) to the Tropics (e.g., Asner et al., 2012). As opposed to passive remote sensing systems that rely on reflected solar radiation, lidar instruments utilize their own active light source to survey the $x, y, z$ coordinates of object surfaces at a rate of up to one million survey points per second. To determine the $x, y, z$ coordinates, lidar instruments measure the inclined distance and angle to each survey 
point (Van Genechten et al., 2008; Eitel et al., 2013). Based on the distance and measured angles, the $x, y$, and $z$ coordinates can be calculated for each point using trigonometric principles (Eitel et al., 2013). The $x, y, z$ coordinates surveyed by lidar can then be used to derive physical proxies of plant biomass such as crop height, volume, and LAI (Zheng and Moskal, 2012; Eitel et al., 2014; Pittman et al., 2015;

Hoffmeister et al., 2015). These physical proxies are relatively unaffected by factors such as foliar biochemistry, illumination geometry, and background reflectance that confound spectral index to biomass relationships. Hence, relationships between lidar-derived biomass proxies such as crop height and crop biomass are more analogous to field-based allometry and are thus relatively transferable across space and time. For example, Eitel and colleagues (2014) showed that a simple linear model could be spatially and temporally transferable in the prediction of dry biomass of wheat based on TLS height metrics. This is in agreement with findings by Tilly et al. (2015) who showed that a simple regression model for predicting dry biomass of paddy rice based on TLS derived crop height provided reliable estimates across space and time with $\mathrm{R}^{2}$ values ranging between 0.60 to 0.90 and 0.56 to 0.85 for linear and exponential models, respectively. Importantly however, both of these examples suggest that relationships between lidar metrics and biomass are species-specific. For studies in structurally similar systems, the spatial and temporal transferability of crop height to biomass relationships constitutes a clear advantage when compared to spectral index based biomass estimates that require frequent and costly recalibration (e.g., Baret and Guyot, 1991; Verstraete et al., 1996; Foody et al., 2003; Eitel et al., 2014; Greaves et al., 2015; Tilly et al., 2015; Fekety et al., 2015).

Despite the great promise of lidar to provide accurate and physically based plant biomass information, airborne lidar data acquisition can be expensive and often lacks temporal resolution, limiting its use as a viable biomass monitoring approach (Wallace et al., 2012). However, recent technological advancements are now enabling automated hypertemporal lidar acquisition at a lower financial cost. For acquiring hypertemporal lidar datasets at the plot scale, autonomously operating terrestrial laser scanners (ATLS) have recently become available (Eitel et al., 2013; Portillo-Quintero et al., 2014; Culvenor et al., 2014; Griebel et al., 2015). After initial calibration, these instruments could replace manual and labor- 
intensive biomass sampling by providing a novel solution for automated estimation of biomass (e.g., Eitel

101 et al., 2014; Tilly et al., 2015) and plant structural characteristics. For example, Eitel et al. (2013)

102 described a low-cost (< US\$12000) ATLS that proved suitable for capturing daily changes in plant

103 structure throughout a period of 17 days during fall leaf drop in a mixed conifer/quaking aspen (Populus

104 tremuloides) forest stand. Similarly, Portillo-Quintero et al. (2014) used an ATLS for mapping daily

105 changes in Plant Area Index (PAI) for a period of 22 days during leaf drop in a boreal mixed forest.

106 Scaling plot-level biomass data to broader areas is of importance to many applications. To scale

107 the plot-level plant biomass information derived with an ATLS to the landscape, passive spectral data

108 could be used. This process requires that a simple calibration equation be established between

109 dimensionless spectral indices for pixels within the ATLS footprint and biomass estimates derived from

110 ATLS measurements (Rall and Knox, 2004; Portillo-Quintero et al., 2014; Hoffmeister et al., 2015).

111 Establishing such a calibration based on ATLS data would not only allow replacing manual and labor-

112 intensive ground validation measurements with automated plant structural measurements but would also

113 alleviate difficulties in accurately obtaining field calibration/validation of biomass amounts for satellite

114 pixels with a ground instantaneous field of view (GIFOV) commonly surpassing $20 \mathrm{~m}^{2}$ in area (e.g.,

115 Verstraete et al., 1996; Ustin et al., 2004).

116 Despite the need, to date relatively little is known regarding the suitability of an ATLS for

117 monitoring plant growth dynamics and calibrating satellite imagery to map crop biomass. To address this

118 knowledge gap, the two specific objectives of this study were to assess the suitability of an ATLS to i)

119 monitor crop growth dynamics and ii) calibrate satellite imagery for estimating and mapping crop

120 biomass. 


\subsection{Study site}

For testing the suitability of the ATLS for monitoring crop growth dynamics (Objective 1), soft

127 white spring wheat (Triticum aestivum spp.) was grown in 2014 following soft white winter wheat in 128 eighteen $100 \mathrm{~m}^{2}(10 \mathrm{~m} \times 10 \mathrm{~m})$ plots with $19 \mathrm{~cm}$ row spacing at the Washington State University Cook 129 Agronomy Farm (CAF) near Pullman, Washington, USA ( $N$ 46.7805, $W$ 117.0855). The 18 research plots were divided into three fields (hereafter referred to as Field A, Field B, and Field C) to encompass a wide range of growth conditions and hence crop growth dynamics (see Magney et al., 2016a). Additionally, four "top-dressed" $\mathrm{N}$ application rates were applied at each of the three fields $\left(0,40,80\right.$, and $\left.120 \mathrm{~kg} \mathrm{ha}^{-1}\right)$ using granular urea $(46 \% \mathrm{~N})$ three days post-seeding (similar to Eitel et al. 2014). Soil was sampled for inorganic $\mathrm{N}\left(\mathrm{NO}_{3}\right.$ and $\left.\mathrm{NH}_{4}\right)$ prior to $\mathrm{N}$ application; residual $\mathrm{N}$ in the soil did not significantly differ across the plots $(\mathrm{p}<0.05)$. The study site has silt load soils developed in loess deposits with some ash (fine-silty, mixed, superactive, mesic Pachic Ultic Haploxerolls, Soil Survey Staff, 2013). CAF is a dryland site

137 without irrigation, and soil permeability is moderate to high. Average annual precipitation ranges from 138260 to $610 \mathrm{~mm}$, and the average available water capacity through the entire soil profile is about $29 \mathrm{~cm}$ 139 (Soil Survey Staff, 2013).

For testing the suitability of the ATLS for calibrating satellite-based biomass estimates (Objective

141 2), soft white spring wheat (Triticum aestivum L.) was grown in 2013 within one 36 ha commercial

142 dryland wheat field located approximately 10 kilometers east of the research plots, near Moscow, Idaho 143 (hereafter referred to "Moscow Farm"). Annual precipitation ranges between 580 to $730 \mathrm{~mm}$ and the soil 144 type is Southwick silt loam (Soil Survey Staff, 2015). 


\subsection{ATLS instrumentation and data collection}

The ATLS used in this study was a system described in detail by Eitel et al. (2013). The relatively low-cost ( US\$12,000) ATLS consists of a time-of-flight laser rangefinder (optoNCDT ILR 1191, Micro-Epsilon Messtechnik GmbH \& Co. KG, Ortenburg, Germany), circular level, electronic pan-tilt

152 unit, tribrach, datalogger, and power supply (battery and 100 Watt solar panel) (Figure 1). The laser rangefinder employs a near infrared $(905 \mathrm{~nm})$ laser with $1.7 \mathrm{mrad}$ beam divergence and has a maximum range of $150 \mathrm{~m}, 300 \mathrm{~m}$, and $500 \mathrm{~m}$ for surfaces with reflectance at $905 \mathrm{~nm}$ of $6 \%, 10 \%$, and $90 \%$, respectively (Table 1).

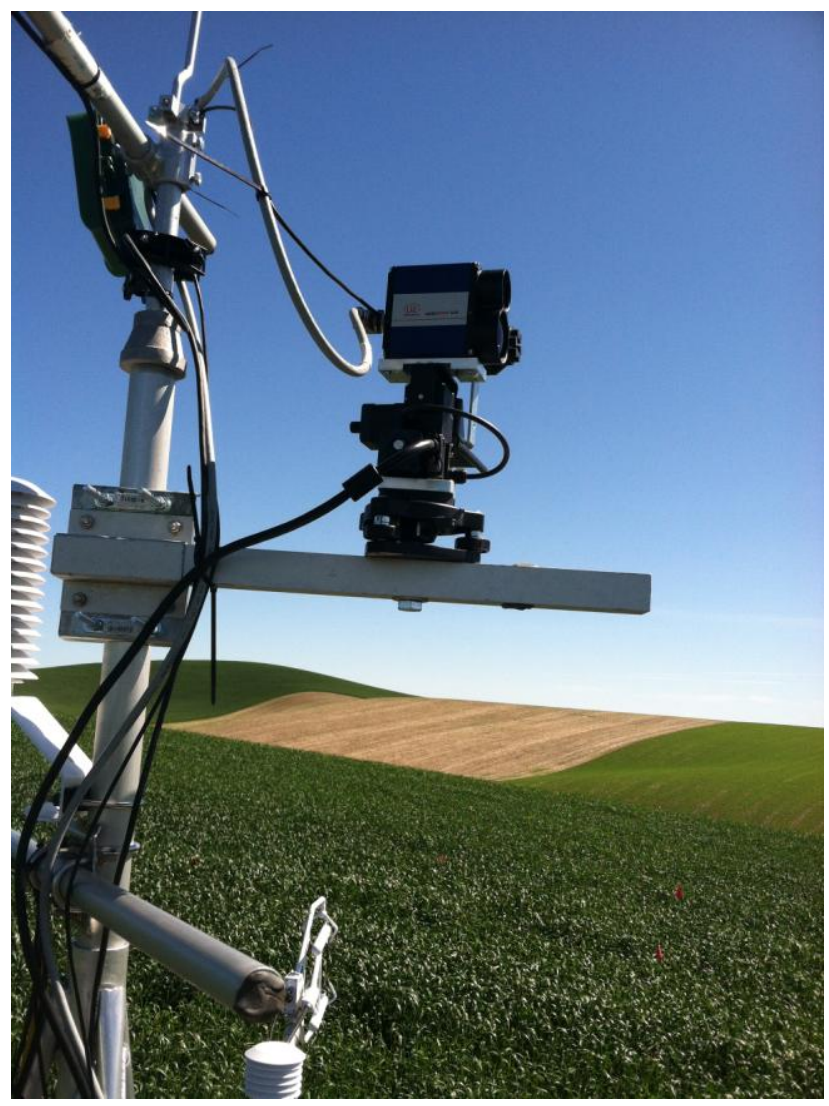

Figure 1. Autonomously operating terrestrial laser scanner (ATLS) mounted on a tower structure. For more details on the design of the ATLS, please refer to Eitel et al. (2013). 
171 Table 1. Technical specifications of time-of-flight laser rangefinder (optoNCDT ILR 1191, Micro-

172 Epsilon Messtechnik GmbH \& Co. KG, Ortenburg, Germany).

\begin{tabular}{|l|l|}
\hline Laser wavelength & $905 \mathrm{~nm}$ \\
\hline Laser divergence & $1.7 \mathrm{mrad}$ \\
\hline Light spot geometry & $45 \mathrm{x} 41 \mathrm{~mm}$ at $10 \mathrm{~m}$ \\
\hline Linearity & $\pm 20 \mathrm{~mm}($ at measurement output $100 \mathrm{~Hz})$ \\
& $\pm 60 \mathrm{~mm}($ at measurement output $2 \mathrm{kHz})$ \\
\hline Repeatability & $\leq 5 \mathrm{~mm}$ \\
\hline Operating temperature & $-40^{\circ} \mathrm{C}$ to $+60^{\circ} \mathrm{C}$ \\
\hline
\end{tabular}

173

To monitor crop growth dynamics, one ATLS was installed at each of the three experimentally manipulated field sites (i.e., Field A, Field B, and Field C) and at the Moscow Farm. Each ATLS was installed on a tower structure about 3 meters above the ground. To obtain point clouds of the "bare earth", measurements were initialized immediately after seeding in April. The vertical and horizontal angular

178 step resolution of the pan-tilt unit was set to $2.27 \mathrm{mrad}$. The scan duration for each site was

179 approximately 28 hours, resulting in unique lidar point cloud information of the crop canopy recorded 180 almost daily between April and the conclusion of ATLS measurements in August.

\subsection{Monitoring crop growth dynamics}

At each of the 18 plots, the average of three crop height measurements taken with a meter stick on May $29^{\text {th }}$, June $4^{\text {th }}$, June $26^{\text {th }}$, and July $3^{\text {rd }}$ was recorded. Regardless of growing stage, the distance between the highest point in the canopy and the ground were used for height measurements. Due to the relatively small size of the plots and locally homogeneous nature of wheat cropping systems, we assume that crop height variance within each plot was minimal. At the same locations as crop height measurements, three LAI measurements were taken on May $29^{\text {th }}$, June $4^{\text {th }}$, June $19^{\text {th }}$, June $26^{\text {th }}$, and July $3^{\text {rd }}$ with a Li-Cor LAI-2000 Plant Canopy Analyzer (Li-Cor, Lincoln, NE, USA, following Magney et al., 
measuring crop biomass at each of the plot locations, plant material was harvested on each sampling date

193 from a $1 \mathrm{~m}^{2}$ subplot, dried, and weighed to determine crop dry mass.

To derive crop height of the sampled areas from ATLS data, 3x3 meter areas of interest (AOIs)

were chosen that received the same $\mathrm{N}$ treatments and were exposed to the same environmental growth were visually identified in the post-sampling ATLS point cloud and the AOI was placed adjacent to it

198 (Figure 2A).

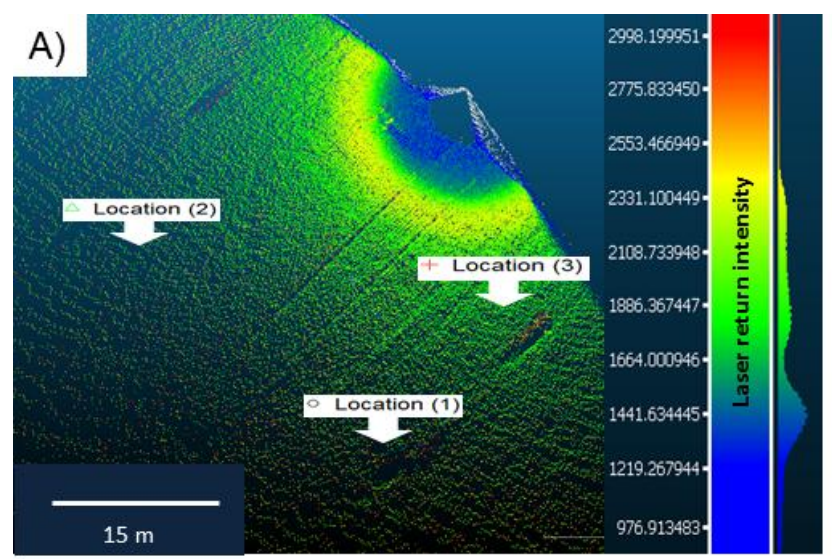

\section{B)}

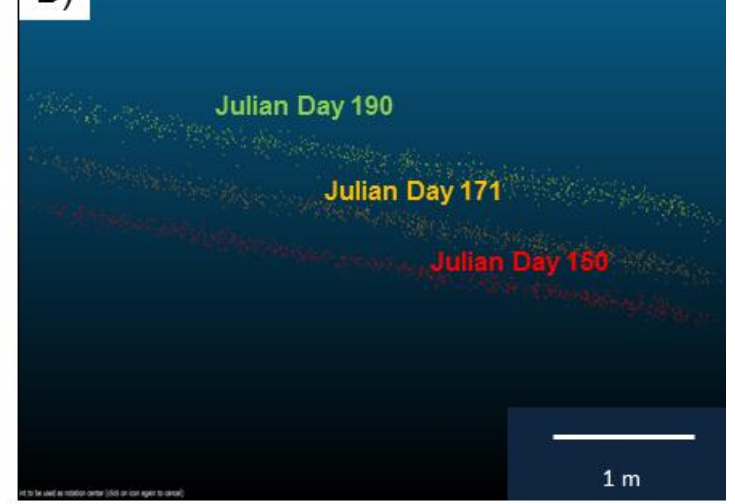

207

C)

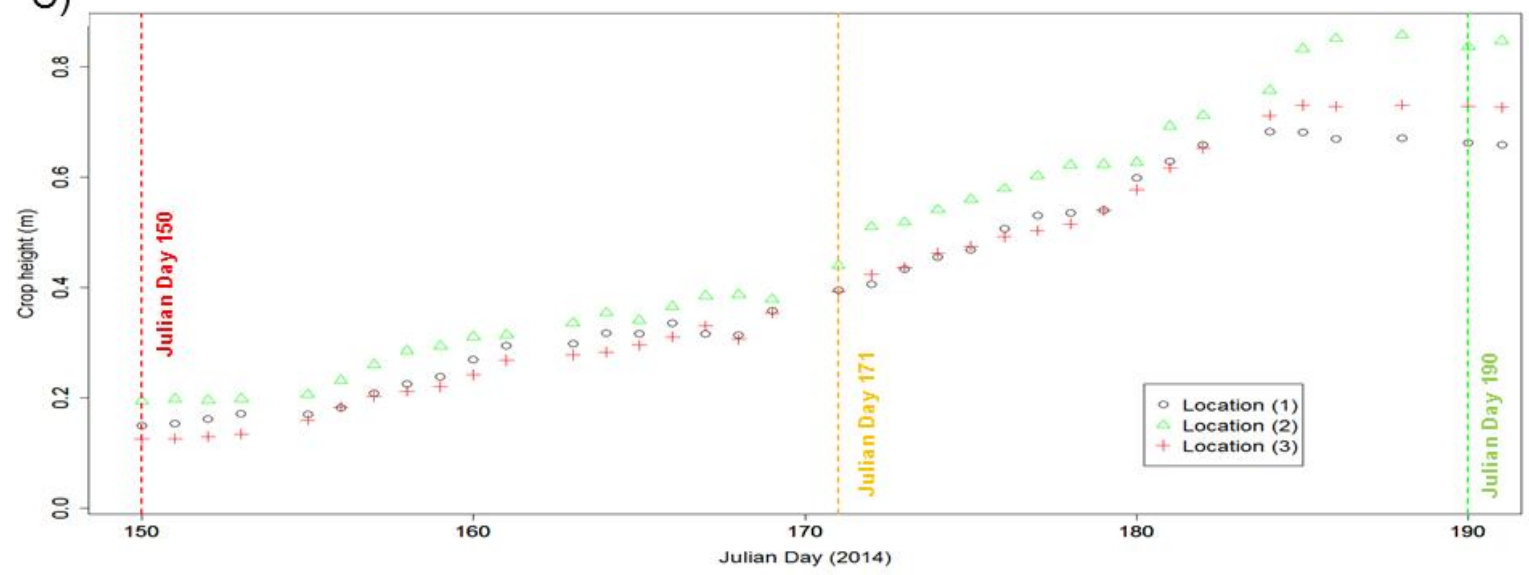

214 Figure 2. Illustration of hypertemporal lidar data from an autonomously operating terrestrial laser

215 scanner (ATLS) for studying crop growth dynamics at very high spatial and temporal resolution. Figure

2162 A shows an example of an ATLS point cloud, Figure 2B shows a cross section of the wheat canopy at

217 location 1 (see Figure 2A for location labels) acquired during Julian day 150, Julian day 171, and Julian 
day 190 and Figure 2C shows the wheat canopy height changes derived from ATLS data throughout the growing season at location 1, 2, and 3 (see Figure 2A for location labels).

Four of the 18 sampling plots could not be clearly identified from the point cloud and hence only

22214 out of 18 sampling plots were considered for the analysis. The point clouds associated with each AOI

223 and sampling date were then loaded into a program (available upon request from the authors) written in

224 the in the Interactive Data Language (IDL) software package (Version 8.0, ITT Visual Information

225 Solutions) to calculate crop height based on the surface differencing approach (e.g., Loudermilk et al.,

226 2009; Eitel et al., 2014; Greaves et al., 2015). In surface differencing, a digital terrain model (DTM) is

227 subtracted from a digital surface model (DSM) to calculate vegetation height. Here, the DTM was derived

228 from a "bare earth" ATLS scan acquired directly after seeding (i.e. before the start of the growing

229 season), and a DSM was derived from ATLS scans performed on each subsequent sampling date. To

230 derive the DTM and the DSMs for each AOI and sampling date, the program grids each ATLS point

231 cloud onto an arbitrarily subdivided $0.05 \mathrm{~m} \times 0.05 \mathrm{~m}$ surface. The $z$ value assigned to each grid cell by the

232 program is the minimum (for DTM) or maximum (for DSM) $z$ value within a search radius from the

233 center of the grid cell. If there is no $z$ value within the search radius, the assigned $\mathrm{z}$ value is linearly

234 interpolated based on surrounding $z$ values. The search radius for both the DTM and DSM was optimized

235 by varying the search radius between 1 and $30 \mathrm{~cm}$ in $1 \mathrm{~cm}$ intervals. Finally, the laser-derived crop height

236 for the AOI is determined by calculating the mean of the height differences between the DSM and the

237 DTM grid cells.

To assess the suitability of the ATLS for monitoring crop growth dynamics, we used R 2.3.2 (R

239 Core Team, 2015) to fit both linear (using the 'lm' function) and nonlinear (using the 'nls' function)

240 regression models between i) measured crop height and ATLS-derived crop height, ii) crop biomass and

241 LAI and iii) crop biomass and ATLS-derived crop height. All models were fit with untransformed data

242 and nonlinear regression models had the following general form: 
where $\mathrm{y}$ is the dependent variable (crop biomass), $\mathrm{x}$ the independent variable, and $\mathrm{a}$ and $\mathrm{b}$ are

245 allometric constants. Goodness of fit was evaluated based on the coefficient of determination $\left(\mathrm{r}^{2}\right)$ and the 246 root mean square error (RMSE).

\subsection{Calibrating satellite imagery for estimating crop biomass}

To assess the suitability of ATLS-derived structural metrics for calibrating satellite data, we used level 3A RapidEye images, which have already been radiometrically and geometrically corrected

251 (RapidEye, AG 2013). The RapidEye satellite imagery of the Moscow Farm was acquired during the

252 tillering (Zadoks 37) and heading (Zadoks 50) crop growth stage on June 15 and June 29, 2013,

253 respectively (for more details on Zadoks scale, please refer to Zadoks et al., 1974).), We calculated the

254 Normalized Difference Vegetation Index (NDVI; Tucker, 1979) and the Normalized Difference Red-

255 Edge index (NDRE; Gitelson and Merzlyak, 1994) as follows:

$$
\begin{aligned}
& \mathrm{NDVI}=\left(\mathrm{R}_{\text {band5 }}-\mathrm{R}_{\text {band3 }}\right) /\left(\mathrm{R}_{\text {band5 }}+\mathrm{R}_{\text {band3 }}\right) \\
& \mathrm{NDRE}=\left(\mathrm{R}_{\text {band5 }}-\mathrm{R}_{\text {band4 }}\right) /\left(\mathrm{R}_{\text {band5 }}+\mathrm{R}_{\text {band4 }}\right)
\end{aligned}
$$

where band numbers refer to RapidEye band 3 (red: 630-685 nm), band 4 (red-edge: 690-730 nm), and band 5 (near-infrared: $760-850 \mathrm{~nm}$ ). Both of these indices were selected due to their well-established sensitivity to variation in plant biomass (e.g., Tucker et al., 1979; Binnary et al., 1995; Torino et al., 2012; Tavakoli et al., 2014; Amaral et al., 2014; Kross et al., 2015), particularly for capturing variance in wheat for this particular study region from RapidEye (Magney et al., 2016b)

To calibrate the dimensionless spectral index values for estimating crop biomass at each of the two acquisition dates, spectral index values for a given pixel were linked to physically based measures of plant structure from the ATLS. For this, four geostationary reflector targets (Leica Geosystems Inc., Heerbrugg, Switzerland) with known geolocations were scanned by the ATLS and used in a translation 
267 and rotation algorithm implemented within an R script to translate the ATLS coordinate system into a

268 geographic coordinate system. This allowed the extraction of ATLS-derived crop height estimates (see

269 section 2.3) associated with the geographic footprint of a pixel defined by its center coordinate and extent

270 (5x5 meters for RapidEye pixels) (Figure 3).

271

272

273

274

275

276

277

278

279

280

281

282

283

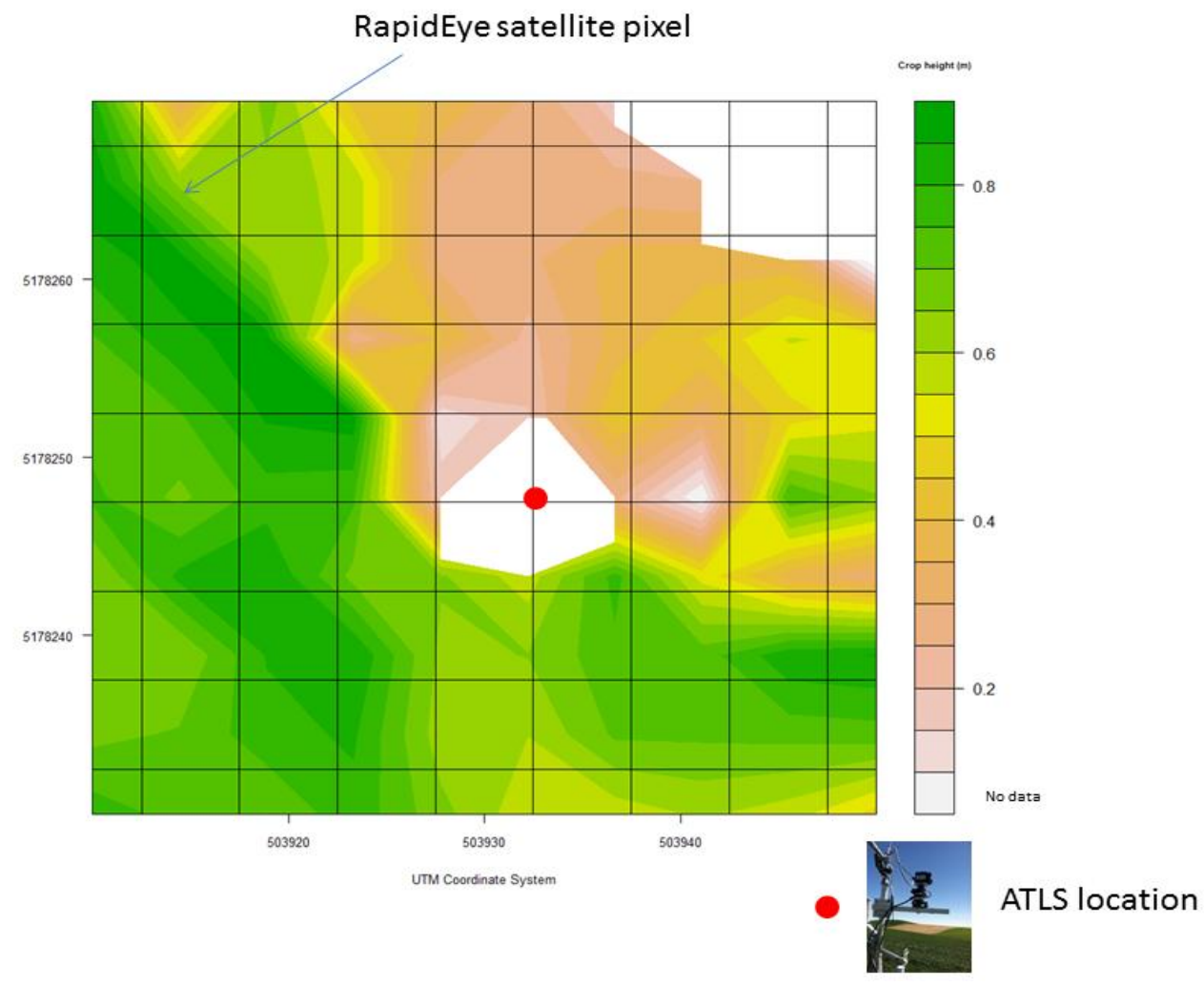

284

285

286

Figure 3. Autonomously operating terrestrial laser scanner (ATLS) derived crop height estimates within

287 the geographic footprint of RapidEye satellite pixels (pixels are shown as squares) defined by their center 288 coordinate and extent (5x5 meters). 
Based on the spectral vegetation index (SVI) values for pixels within the ATLS footprint and associated crop height estimates, a simple calibration equation was fit in $\mathrm{R}$ 2.3.2:

$$
\text { Predicted crop height }=\mathrm{b} 0+\mathrm{b} 1 * \mathrm{SVI}
$$

where $\mathrm{b} 0$ is the intercept and $\mathrm{b} 1$ is the slope. The calibration equation was then applied to the imagery to convert SVI values into crop height estimates. Next, crop height estimates were converted into biomass estimates using the regression model that was fit between crop dry weight and ATLS derived crop height

298 (see section 2.3). To obtain an estimate of the error associated with the resulting satellite-derived biomass estimates, a bootstrap resampling procedure was developed (Efron and Tibshirani, 1993). In the bootstrap procedure, data were resampled from both the dataset used to fit equation 4 , as well as from the dataset used to fit the crop dry weight-crop height linear model (section 2.3) so that the resulting distribution of RMSE values reflects the propagated error from both regression models.

\section{Results and Discussion}

\subsection{Suitability of an ATLS to monitor crop growth dynamics}

$307 \mathrm{~kg} \mathrm{ha}^{-1}$ throughout the growing season (1431.24 $\pm 1013.90 \mathrm{~kg} \mathrm{ha}^{-1}$; mean \pm standard deviation) (Figure 4).

308 Similarly, manually measured crop height increased from a minimum of $0.14 \mathrm{~m}$ at the beginning of the 309 growing season to a maximum of $0.93 \mathrm{~m}$ at the end of the growing season $(0.47 \pm 0.27 \mathrm{~m}$; mean \pm standard 310 deviation).

Manually measured crop biomass and manually measured crop height showed a strong $\left(\mathrm{r}^{2}=0.88\right.$,

312 RMSE $=386.50 \mathrm{~kg} / \mathrm{ha}$, see Fig. 4A) statistically significant $(\mathrm{p}<0.0001)$ correlation with each other, with

313 the biomass and height values varying among the differently fertilized plots. For example, the crop height 314 during the June $4^{\text {th }}$ sampling campaign ranged between $0.08 \mathrm{~m}$ and $0.32 \mathrm{~m}$. The ATLS captured this 
manually measured spatial and temporal variability in crop growth, as illustrated in Fig. 2B and 2C.

Figure 2B shows a cross-section through ATLS point clouds acquired during Julian Day 150, Julian Day 171, and Julian Day 190 with increasing point cloud heights at later growth stages. Similarly, Figure 2C shows ATLS-derived crop height changes over time for three different plot locations. Though crop heights at all three different plot locations show the same growth trend, spatially and temporally distinct crop growth patterns existed according to plot location. For example, the crop at location 2 (see Figure $2 \mathrm{~A}$ for location labels) continued to grow from Julian day 184 to 186 , in contrast to the crop at locations 1 and 3, which reached its maximum height on Julian day 184.
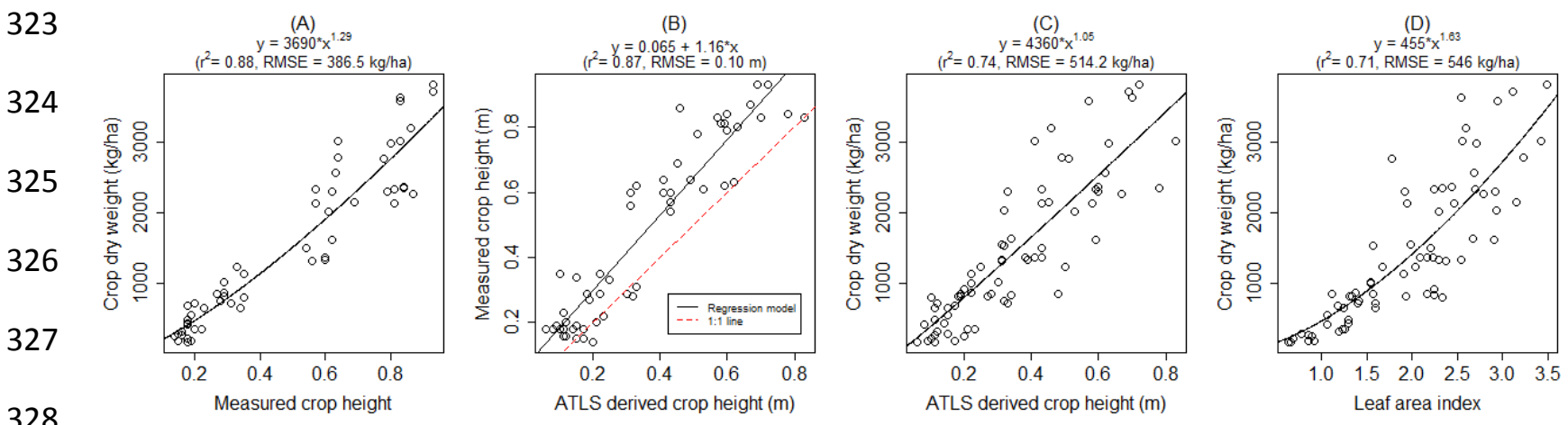

329

Figure 4. Relationships between A) crop dry weight and measured crop height, B) measured crop height and autonomously operating terrestrial laser scanner (ATLS) derived crop height, C) crop dry weight and ATLS derived crop height, and D) crop dry weight and leaf area index.

The degree to which the ATLS captured variations in crop growth was statistically quantified by linear regression models that related ATLS-derived biomass metrics to both manually measured crop height and manually measured crop biomass (Fig. 4B-C). ATLS-derived crop height was strongly correlated $\left(r^{2}=0.87\right.$, and RMSE $\left.=0.10 \mathrm{~m}\right)$ with manually measured crop height (Fig. 4B). These results are similar to findings by Hoffmeister et al. (2015) who showed an RMSE of 0.10 meters between manually measured and terrestrial lidar-derived canopy height of sugar beets. When compared to manual crop height measurements, the ATLS underestimated crop height (Fig. 4B). This could be explained by 
the laser return integrating between the heights of different surfaces (e.g., top of canopy, flag leaf of

341 wheat plant, and soil) that are within the ground instantaneous field of view of the laser beam. This results

342 in a mixed edge return (also known as mixed pixel or air return) inherent in all laser-based ranging

343 methods, where the recorded distance is neither the distance to the foreground object nor the background

344 object, but rather the distance to a location (sometimes referred to as a "phantom object") that lies

345 somewhere between the objects (Hebert and Krotkov, 1992; Tuley et al., 2005).

The ATLS-derived crop height explained almost three-quarters of the variability in destructively sampled crop biomass $\left(\mathrm{r}^{2}=0.74, \mathrm{RMSE}=514.20 \mathrm{~kg} \mathrm{ha}^{-1}\right)($ Fig. $4 \mathrm{C})$ and showed a slightly stronger

348 correlation to crop biomass than did the LAI-2000 derived LAI values, which are widely used to non-

349 destructively estimate crop biomass $\left(\mathrm{r}^{2}=0.71, \mathrm{RMSE}=546 \mathrm{~kg} \mathrm{ha}^{-1}\right)($ Fig. 4D). Some of the unexplained

350 variability between dry biomass and ATLS-derived crop height might be explained by the relatively large 351 beam divergence (1.7 mrad) of the ATLS, resulting in a beam diameter (i.e. ground instantaneous field of 352 view) of $>45 \mathrm{~mm}$ at $10 \mathrm{~m}$ and $>155 \mathrm{~mm}$ at $75 \mathrm{~m}$. This relatively large beam divergence does not allow 353 small canopy components to be resolved, particularly at larger (>10 m) distances between the ATLS and 354 the surveyed crop. However, even though in this study the distance between the ATLS and surveyed plots 355 varied between $5-40 \mathrm{~m}$ (associated beam diameter: $37 \mathrm{~mm}-96 \mathrm{~mm}$ ), this variable had a minimal effect 356 on the regression model as shown by a non-significant ( $\mathrm{p}$-value $>0.05$ ) effect of "distance" when 357 included as a covariate in the regression model. The strength of the relationship between biomass and ATLS-derived crop height weakened with 359 increasing biomass as shown by the heteroscedastic behavior of the regression model (Figure 4C). One 360 explanation for the heteroscedastic model behavior could be that ATLS derived crop height does not 361 account for differential crop density. In other words, although the crop height might be the same between 362 different plots, crop density might differ. This explanation appears to be unsatisfactory, however, because 363 the relationship between crop biomass and LAI shows the same heteroscedastic behavior even though 364 LAI measurements account for variations in crop density. 
366 different fields and treatments that become more pronounced during later growth stages. Even though

367 crop height, LAI, and crop density might be similar between plots, differences in environmental growth

368 conditions such as water availability, nutrient availability, and air temperature might result in phenotypic

369 variation (e.g., in plant tissue density) that cannot be detected using either the ATLS or the LAI-2000.

370 The strength of the relationship between crop biomass and ATLS-derived crop height was

371 unaffected by the upper and lower search radius used to identify the minimum and maximum $\mathrm{z}$ values to

372 calculate the DTM and DSM, respectively (Fig. 5). This finding differs from previous work that showed

373 that the search radius had strong effects on terrestrial lidar derived biomass estimates of different types of

374 plant canopies (Eitel et al., 2014; Greaves et al., 2015). A likely cause for this discrepancy is that in

375 contrast to previous studies, there is no vegetation in the "bare-earth" ATLS scans to confound the

376 identification of ground points. Furthermore, because the canopy is relatively uniform, this optimization

377 procedure is likely unnecessary. 


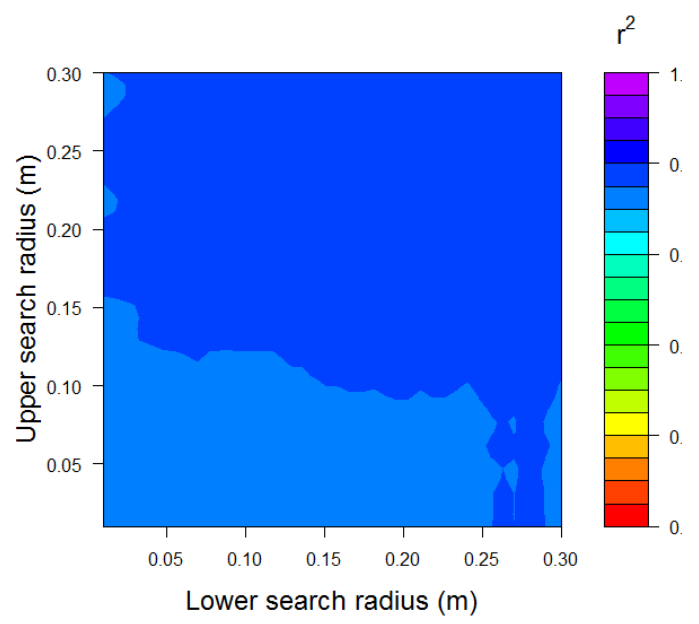

Figure 5. Search radii for fitting the digital terrain model (lower search radius) and digital surface model (upper search radius) and resulting coefficient of determination $\left(\mathrm{r}^{2}\right)$ for the regression model fit between the observed crop dry weight and autonomously operating terrestrial laser scanner (ATLS) derived crop 397 height.

\subsection{Suitability of an ATLS to calibrate satellite-based crop biomass estimates}

The ATLS-derived crop height providedreliable biomass estimates of the wheat crop (Figure 4C).

400 While the spatial extent of ATLS measurements is confined to the plot scale ( $<50 \times 50$ meters), this extent

401 does allow for physically based ATLS crop height estimates to be directly compared with passive satellite 402 data to estimate and then map crop biomass at broader scales. Our results showed that satellite-derived 403 NDRE and NDVI values were correlated $\left(\mathrm{r}^{2}>=0.63\right.$, RMSE $\left.<=0.06 \mathrm{~m}\right)$ with ATLS-derived crop height 404 estimates on both June $15^{\text {th }}, 2013$ and June 29, 2013 (Fig. 6). These relationships are considerably 405 stronger than previously observed relationships between NDVI and terrestrial lidar derived crop height 406 during similar crop growth stages in winter barley and winter wheat $\left(r^{2}<0.26\right)$ (Hoffmeister et al., 2015). 

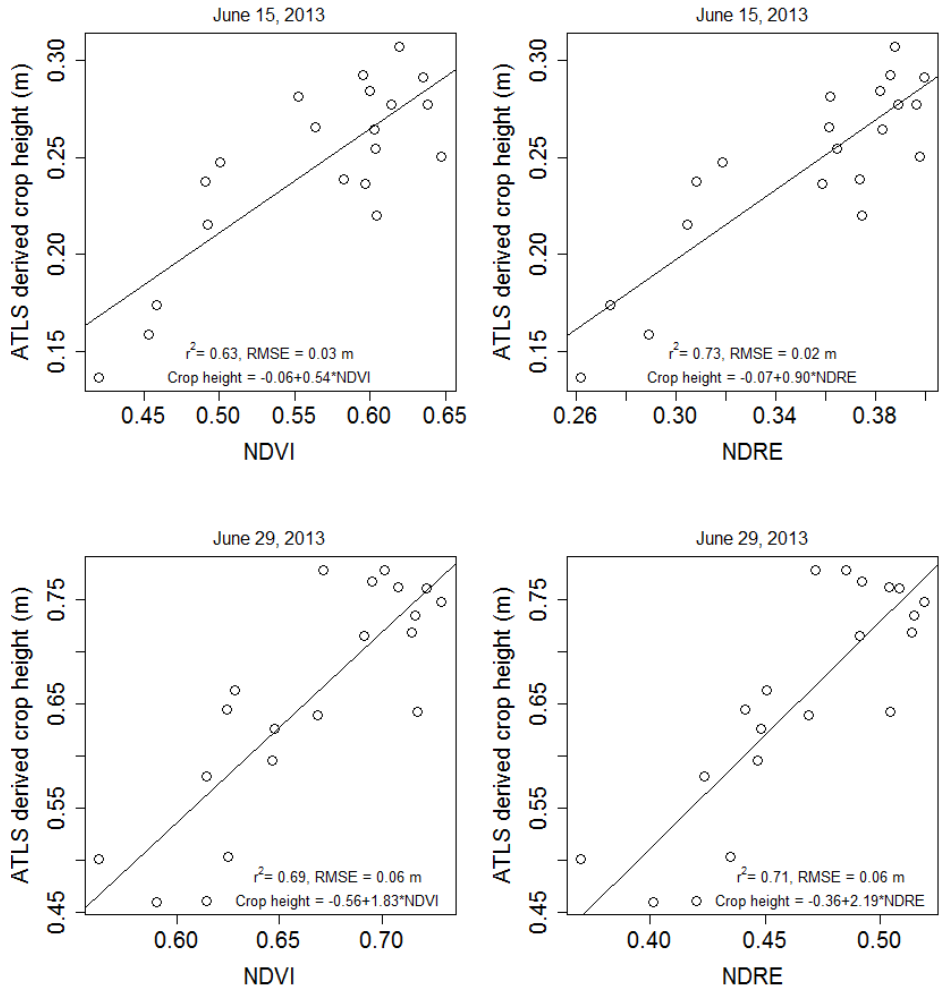

420

421

Figure 6. Relationships between autonomously operating terrestrial laser scanner (ATLS)- derived crop

422 height and spectral vegetation indices during the jointing (Zadoks 37; June 15, 2013) and heading

423 (Zadoks 50; June 29, 2013) growth stage.

The reason for this discrepancy could be differences in the range of height values within the farm fields. The wider the range of crop height values throughout a field for a given acquisition date, the more likely it is to detect and model a trend in the relationship between spectral vegetation indices (e.g., NDVI and NDRE) and crop height. Some of the data variance could be explained by minor positional inaccuracies in both the satellite and ATLS data, which may not allow perfect co-registration of satellite pixels with ATLS-derived crop height estimates.

431 findings showing that NDRE is more sensitive to variations in biomass and less prone to saturation at 432 higher biomass values than NDVI (Viña and Gitelson, 2005; Torino et al. 2012; Amaral et al., 2014). The 433 need to frequently re-calibrate spectral index values for estimating crop biomass is illustrated by the 
434 regression models that show different slopes and intercepts for each acquisition date. For example, the

435 slope and intercept for the regression model between ATLS-derived crop height and NDVI on June $15^{\text {th }}$ is

$436-0.06$ and 0.54 , respectively, and on June $29^{\text {th }}$ it is -0.56 and 1.83 , respectively. This result further

437 confirms the inconsistent nature of relationships between spectral index values and crop properties

438 highlighted in other works (e.g., Kross et al., 2015; Fitzgerald et al., 2010; Eitel et al., 2008, Hatfield et

439 al., 2008).

440 This strongly empirical relationship between spectral index values and crop biomass indicates

441 that innovative methods are needed to effectively calibrate satellite-based biomass estimates. The

442 relationships between crop biomass and ATLS-derived crop height (Fig. 3C) and between spectral index

443 values and ATLS-derived crop height (Fig. 6) suggest that the ATLS could be used for such a purpose.

444 For the commercial farm field near Moscow, NDVI-based biomass estimates calibrated with ATLS data

445 showed a biomass error of 796.18 and $745.11 \mathrm{~kg} \mathrm{ha}^{-1}$ (RMSE) during the wheat jointing (Zadoks 37) and

446 heading (Zadoks 50) growth stages, respectively. The biomass error decreased to 730.96 and $727.60 \mathrm{~kg}$

$447 \mathrm{ha}^{-1}$ (RMSE), respectively, when NDRE was used instead of NDVI. Figure 7 shows biomass estimates

448 throughout the commercial farm field near Moscow during the heading growth stage, where biomass

449 estimates are based on NDRE calibrated with ATLS data.

450

451

452

453

454

455

456 


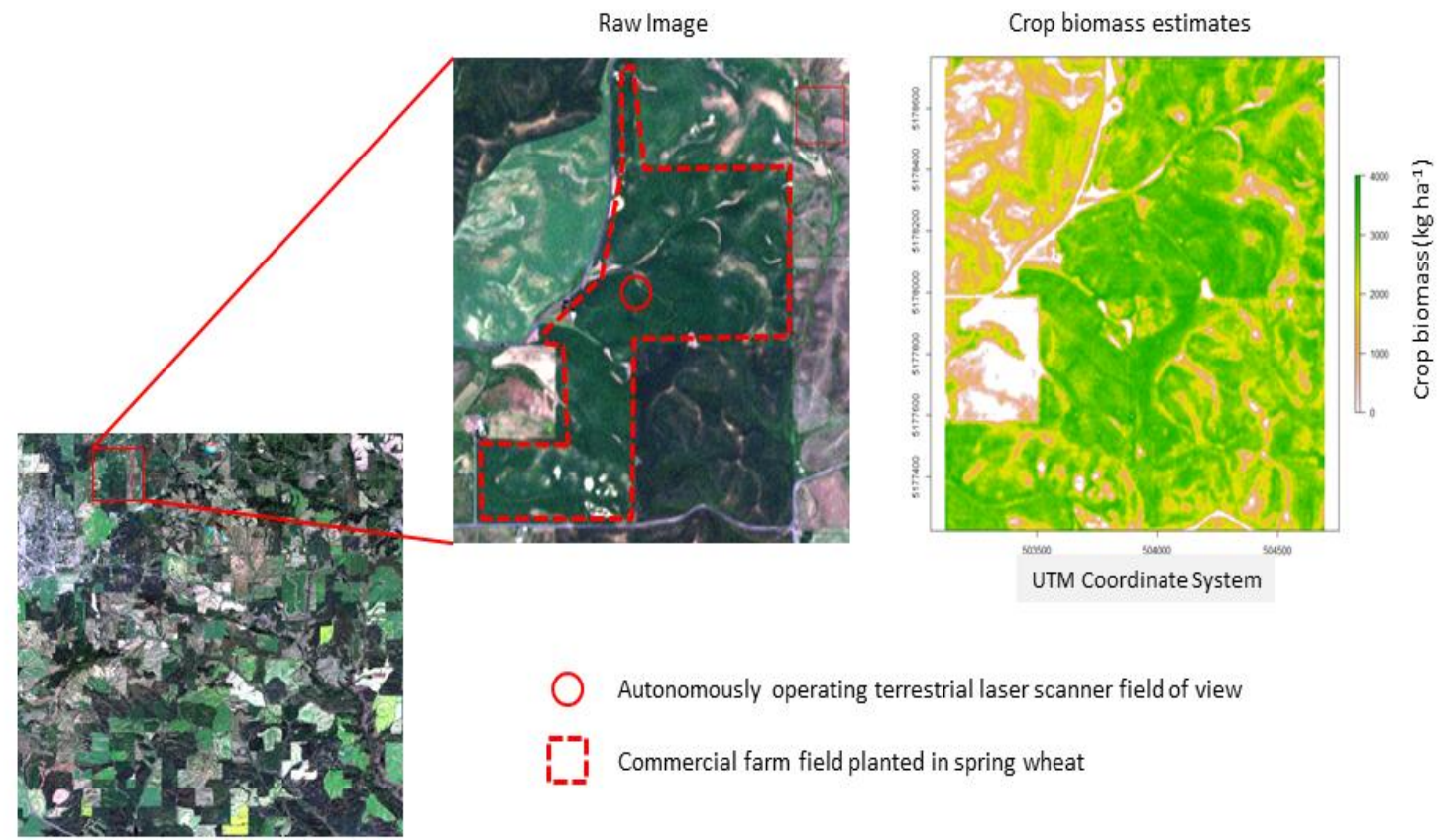

True color RapidEye image

Figure 7. True color RapidEye image of a commercial dryland wheat field near Moscow, Idaho acquired on June 29, 2013 during the heading (Zadoks 50) growth stage of soft white spring wheat and associated crop biomass estimates calibrated with ATLS data (biomass error is $727.60 \mathrm{~kg} \mathrm{ha}^{-1}$ (RMSE)).

\subsection{Limitations, research needs, and opportunities}

The relationship between crop biomass and ATLS derived crop height might be species and even

474 variety specific. For example, Pittman et al. (2015) showed different regression models for predicting dry

475 biomass in alfalfa, Bermuda grass, and wheat based on laser- and ultrasonic-derived crop height. The

476 relationships between ATLS-derived crop height and dry biomass might also change with crop density, 
which can vary due to row spacing or fine scale variation in edaphic conditions and nutrient availability.

478 Yet, given that crop density in this study varied widely due to nutrient and water availability (see Magney

479 et al., 2016a) and that ATLS-derived crop height estimates showed slightly better relationships to crop

480 biomass than LAI measurements that take variations in crop density into account, variations in crop

481 density seem to be a lesser concern. Nevertheless, further investigations are needed to explicitly examine

482 the effects of crop density, plant tissue density, crop species, and crop varieties on the accuracy and

483 reliability of the relationships between ATLS-derived crop height and dry biomass. Further, this study

484 only focuses on crop height as a lidar proxy for crop biomass. Though beyond the scope of this study,

485 other metrics could be derived from ATLS data to obtain potentially more accurate proxies for crop

486 biomass such as fractional crop cover and canopy gap fraction, particularly where the ATLS views the

487 crops at relatively low view zenith angles (Zheng et al. 2012). Further, recent research suggests that the

488 laser return intensity recorded by lidar instruments for one or more wavelengths might further increase the

489 suitability of ATLS for crop monitoring, be useful (Eitel et al., 2010, Eitel et al., 2011, Gaulton et al.,

490 2013; Danson et al., 2014; Eitel et al., 2014; Magney et al., 2014, Eitel et al., 2016). Of particular interest

491 for agricultural applications might be the laser return intensity of a green scanning lidar, which has been

492 shown to provide information about foliar chlorophyll concentration (Eitel et al., 2010), foliar nitrogen

493 (Eitel et al., 2011; Eitel et al., 2014), and even plant photoprotective capacity (Magney et al., 2014).

494 Hence, even though this might decrease the range, replacing the near-infrared (905 nm) laser used in this

495 study with a green $(532 \mathrm{~nm})$ laser might allow monitoring of not only crop structure, but also foliar

496 biochemistry and crop physiological function.

The results of this study provide initial evidence of the suitability of the ATLS for calibrating satellite-based biomass estimates. With further development, web-enabled ATLS monitoring networks across growing regions could make it feasible to deliver biomass estimates in near real time that are 
501 biomass maps for agricultural decision makers, representing a major technological step forward since 502 such information is currently difficult to obtain at scales relevant for agricultural decision making.

\section{Summary and conclusion}

The objectives of this study were twofold - to first assess the suitability of an ATLS to monitor

505 crop growth dynamics, and then to calibrate satellite imagery using these physically-based relationships to

506 better scale and map crop biomass. The results suggest that an ATLS is suitable for monitoring crop

507 growth dynamics. Crop height information derived from a total of three ATLSs reliably tracked changes

508 in dry biomass $\left(r^{2}=0.74, \mathrm{RMSE}=514.20 \mathrm{~kg} / \mathrm{ha}\right)$ both throughout the growing season and across a wide

509 range of experimentally manipulated crop growth conditions. These findings, combined with the spatial

510 and temporal transferability of crop height-to-biomass relationships shown in previous studies (Eitel et

511 al., 2014; Tilly et al., 2015) suggests that after initial calibration, ATLS technology could enable

512 automated biomass sampling and reduce the need for traditional labor-intensive manual biomass sampling

513 approaches. ATLS data were also suitable for calibrating satellite-based crop biomass estimates. Satellite-

514 based biomass estimates calibrated with ATLS data captured variability in crop dry biomass throughout a

515 commercial farm field with a biomass error of 730.96and $727.60 \mathrm{~kg} \mathrm{ha}^{-1}$ (RMSE) during the wheat

516 jointing (Zadoks 37) and heading (Zadoks 50) growth stages, respectively. The physically based biomass

517 estimates derived from hypertemporal ATLS data and ATLS-calibrated satellite data constitute important

518 progress in obtaining reliable crop biomass estimates for both agricultural decision-making and research

519 applications. Additional research is needed to further test the robustness of the ATLS for monitoring crop

520 growth dynamics and calibrating satellite-based biomass estimates across different crops, fields, growing

521 seasons, and satellite sensors. 
526 We thank two anonymous reviewers for their thoughtful comments that helped to considerably improve

527 the quality of the manuscript. We further thank Dr. David Huggins for his help with the experimental

528 design and Jyoti Jennewein and Samuel Finch for their assistance in the field. We also thank Dr.

529 Christopher Williams for his help with the bootstrap resampling procedure. This work was supported by

530 Grant Number G14AP00002 from the Department of the Interior, United States Geological Survey to

531 AmericaView and USDA-NIFA Award Nos. 2011-67003-3034 and 2011-68002-30191. TSM was funded

532 by NASA Idaho Space Grant Fellowship (\#NNX10AM75H). Mention of trade names and commercial

533 products does not constitute their endorsement by the University of Idaho or the U.S. Government.

534

535

536

537

538

539

540

541

542

543

544 


\section{References}

Adams, M. S., Gleirscher, E., Gigele, T., \& Fromm, R. (2013). Automated Terrestrial Laser Scanner measurements of small-scale snow avalanches. In International Snow Science Workshop Grenoble Chamonix Mont-Blanc - 2013 (pp. 1060-1065).

Amaral, L. R., Molin, J. P., Portz, G., Finazzi, F. B., \& Cortinove, L. (2015). Comparison of crop canopy reflectance sensors used to identify sugarcane biomass and nitrogen status. Precision Agriculture, $16(1), 15-28$.

Asner, G. P., Mascaro, J., Muller-Landau, H. C., Vieilledent, G., Vaudry, R., Rasamoelina, M., ... van Breugel, M. (2012). A universal airborne lidar approach for tropical forest carbon mapping. Oecologia, 168(4), 1147-1160. doi:10.1007/s00442-011-2165-z

Atzberger, C. (2004). Object-based retrieval of biophysical canopy variables using artificial neural nets and radiative transfer models. Remote Sensing of Environment, 93, 53-67. doi:10.1016/j.rse.2004.06.016

Bannari, A., Morin, D., Bonn, F., \& Huete, A. R. (1995). A review of vegetation indices. Remote Sensing Reviews, 13(1-2), 95-120. doi:10.1080/02757259509532298

Baret, F., \& Guyot, G. (1991). Potentials and limits of vegetation indices for LAI and APAR assessment. Remote Sensing of Environment, 35(2-3), 161-173. doi:10.1016/0034-4257(91)90009-U

Campbell, G. S., Norman, J. M., \& others. (1989). The description and measurement of plant canopy structure. Plant Canopies: Their Growth, Form and Function, 1-19.

Combal, B., Baret, F., Weiss, M., Trubuil, A., Macé, D., Pragnère, A., Wang, L. (2003). Retrieval of canopy biophysical variables from bidirectional reflectance using prior information to solve the illposed inverse problem. Remote Sensing of Environment, 84(1), 1-15. doi:10.1016/S0034- 
Culvenor, D. S., Newnham, G. J., Mellor, A., Sims, N. C., \& Haywood, A. (2014). Automated in-situ laser scanner for monitoring forest Leaf Area Index. Sensors (Basel, Switzerland), 14(8), 1499415008. doi:10.3390/s140814994

Danson, F. M., Gaulton, R., Armitage, R. P., Disney, M., Gunawan, O., Lewis, P., ... Ramirez, A. F. (2014). Developing a dual-wavelength full-waveform terrestrial laser scanner to characterize forest canopy structure. Agricultural and Forest Meteorology, 198-199, 7-14. doi:10.1016/j.agrformet.2014.07.007

Efron, B., \& Tibshirani, R. J. (1994). An introduction to the bootstrap. CRC press.

Ehlert, D., Adamek, R., \& Horn, H.-J. (2009). Laser rangefinder-based measuring of crop biomass under field conditions. Precision Agriculture, 10(5), 395-408. doi:10.1007/s11119-009-9114-4

Eitel, J., Magney, T., \& Vierling, L. (2014). lidar based biomass and crop nitrogen estimates for rapid, non-destructive assessment of wheat nitrogen status. Field Crops ..., 159, 21-32. Retrieved from http://www.sciencedirect.com/science/article/pii/S0378429014000161

Eitel, J. U. H., Long, D. S., \& Gessler, P. E. (2007). Evaluation of Multispectral Based Radiative Transfer Model Inversion to Estimate Leaf Area Index in Wheat (Vol. ASA-CSSA-S, p. ASA-CSSA-SSSA International Annual Meetings, New O).

Eitel, J. U. H., Long, D. S., Gessler, P. E., \& Hunt, E. R. (2008). Combined Spectral Index to Improve Ground-Based Estimates of Nitrogen Status in Dryland Wheat. Agronomy Journal, 100(6), 1694. doi:10.2134/agronj2007.0362

Eitel, J. U. H., Long, D. S., Gessler, P. E., Hunt, E. R., \& Brown, D. J. (2009). Sensitivity of GroundBased Remote Sensing Estimates of Wheat Chlorophyll Content to Variation in Soil Reflectance. 
Eitel, J. U. H., Magney, T. S., Vierling, L. A., \& Dittmar, G. (2014). Assessment of crop foliar nitrogen using a novel dual-wavelength laser system and implications for conducting laser-based plant physiology. ISPRS Journal of Photogrammetry and Remote Sensing, 97, 229-240. doi:10.1016/j.isprsjprs.2014.09.009

Eitel, J. U. H., Vierling, L. A., \& Long, D. S. (2010). Simultaneous measurements of plant structure and chlorophyll content in broadleaf saplings with a terrestrial laser scanner. Remote Sensing of Environment, 114(10), 2229-2237. doi:10.1016/j.rse.2010.04.025

600

601

602

603

604

605

606

607

608

609

610

611

612

613

Eitel, J. U. H., Vierling, L. A., Long, D. S., \& Hunt, E. R. (2011). Early season remote sensing of wheat nitrogen status using a green scanning laser. Agricultural and Forest Meteorology, 151, 1338-1345. doi:10.1016/j.agrformet.2011.05.015

Eitel, J.U.H., Vierling, L., \& Magney, T. (2013). A lightweight, low cost autonomously operating terrestrial laser scanner for quantifying and monitoring ecosystem structural dynamics. Agricultural and Forest Meteorology, 180, 86-96. Retrieved from http://www.sciencedirect.com/science/article/pii/S0168192313001561

Eitel, J. U. H., Höfle, B., Vierling, L. A., Abellán, A., Asner, G. P., Deems, J. S., .. Vierling, K. T. (2016). Beyond 3-D: The new spectrum of lidar applications for earth and ecological sciences. Remote Sensing of Environment, 186, 372-392. doi:10.1016/j.rse.2016.08.018

Estornell, J., Ruiz, L. A., Velázquez-Martí, B., \& Hermosilla, T. (2012). Estimation of biomass and volume of shrub vegetation using lidar and spectral data in a Mediterranean environment. Biomass and Bioenergy, 46, 710-721. doi:10.1016/j.biombioe.2012.06.023

Fekety, P. A, Falkowski, M. J., \& Hudak, A. T. (2014). Temporal transferability of LiDAR-based 
imputation of forest inventory attributes. Canadian Journal of Forest Research, 45(4), 422-435. doi:10.1139/cjfr-2014-0405

Fitzgerald, G., Rodriguez, D., \& O’Leary, G. (2010). Measuring and predicting canopy nitrogen nutrition in wheat using a spectral index-The canopy chlorophyll content index (CCCI). Field Crops Research, 116(3), 318-324. doi:10.1016/j.fcr.2010.01.010

Foody, G. M., Boyd, D. S., \& Cutler, M. E. J. (2003). Predictive relations of tropical forest biomass from Landsat TM data and their transferability between regions. Remote Sensing of Environment, 85(4), 463-474. doi:10.1016/S0034-4257(03)00039-7

Gaulton, R., Danson, F. M., Ramirez, F. A., \& Gunawan, O. (2013). The potential of dual-wavelength laser scanning for estimating vegetation moisture content. Remote Sensing of Environment, 132, 3239. doi:10.1016/j.rse.2013.01.001

Gitelson, A., \& Merzlyak, M. N. (1994). Quantitative estimation of chlorophyll-a using reflectance spectra: experiments with autumn chestnut and maple leaves. Journal of Photochemistry and Photobiology B: Biology, 22(3), 247-252. Retrieved from http://www.sciencedirect.com/science/article/pii/1011134493069634

Greaves, H. E., Vierling, L. A., Eitel, J. U. H., Boelman, N. T., Magney, T. S., Prager, C. M., \& Griffin, K. L. (2015). Estimating aboveground biomass and leaf area of low-stature Arctic shrubs with terrestrial lidar. Remote Sensing of Environment, 164, 26-35. doi:10.1016/j.rse.2015.02.023

Griebel, A., Bennett, L. T., Culvenor, D. S., Newnham, G. J., \& Arndt, S. K. (2015). Reliability and limitations of a novel terrestrial laser scanner for daily monitoring of forest canopy dynamics. Remote Sensing of Environment, 166, 205-213. doi:10.1016/j.rse.2015.06.014 
Haboudane, D., Miller, J. R., Tremblay, N., Zarco-tejada, P. J., \& Dextraze, L. (2002). Integrated narrowband vegetation indices for prediction of crop chlorophyll content for application to precision agriculture. Remote Sensing of Environment, 81, 416-426.

Hatfield, J. L., Gitelson, A. A., Schepers, J. S., \& Walthall, C. L. (2008). Application of spectral remote sensing for agronomic decisions. Agronomy Journal, 100(3 SUPPL.). doi:10.2134/agronj2006.0370c

Hebert, M., \& Krotkov, E. (1992). 3D measurements from imaging laser radars: how good are they? Image and Vision Computing, 10(3), 170-178. doi:10.1016/0262-8856(92)90068-E

Hoffmeister, D., Waldhoff, G., Tilly, N., Bendig, J., \& Bareth, G. (2015). Spatial variability detection of crop height in a single field by terrestrial laser scanning. Precision Agriculture, 267-274. doi:10.3920/978-90-8686-778-3

Jackson, R., \& Huete, A. (1991). Interpreting vegetation indices. Preventive Veterinary Medicine, 11, 185-200. Retrieved from http://www.sciencedirect.com/science/article/pii/S0167587705800042

Jacquemoud, S., \& Baret, F. (1990). PROSPECT: A model of leaf optical properties spectra. Remote Sensing of Environment, 34(2), 75-91. doi:10.1016/0034-4257(90)90100-Z

Jonathan A.R. Rall, R. G. K. (n.d.). Spectral ratio biospheric Lidar. IEEE International IEEE International IEEE International Geoscience and Remote Sensing Symposium, 2004. IGARSS '04. Proceedings. 2004, (1), 1951-1954. doi:10.1109/IGARSS.2004.1370726

Kross, A., McNairn, H., Lapen, D., Sunohara, M., \& Champagne, C. (2015). Assessment of RapidEye vegetation indices for estimation of leaf area index and biomass in corn and soybean crops. International Journal of Applied Earth Observation and Geoinformation, 34, 235-248. 
doi:10.1016/j.jag.2014.08.002

LeWinter, A. L., Finnegan, D. C., Hamilton, G. S., Stearns, L. A., \& Gadomski, P. J. (2014). Continuous Monitoring of Greenland Outlet Glaciers Using an Autonomous Terrestrial lidar Scanning System: Design, Development and Testing at Helheim Glacier. In AGU Fall Meeting Abstracts (Vol. 1, p. 292).

Long, D. S., \& McCallum, J. D. (2013). Mapping straw yield using on-combine light detection and ranging (lidar). International Journal of Remote Sensing, 34(17), DOI:10.1080/01431161.2013.793869.

Loudermilk, E. L., Hiers, J. K., O’Brien, J. J., Mitchell, R. J., Singhania, A., Fernandez, J. C., ... Slatton, K. C. (2009). Ground-based LIDAR: a novel approach to quantify fine-scale fuelbed characteristics. International Journal of Wildland Fire, 18(6), 676. doi:10.1071/WF07138

Magney, T. S., Eitel, J. U. H., Vierling, L. A., \& Huggins, D. R. (2016a). Proximal NDVI derived phenology improves in-season predictions of wheat quantity and quality. Agricultural and Forest Meteorology.

Magney, T. S., Eitel, J. U. H., \& Vierling, L. A. (2016b). Mapping wheat nitrogen uptake from RapidEye vegetation indices. Precision Agriculture, 1-23. doi:10.1007/s11119-016-9463-8

Magney, T. S., Eusden, S. A., Eitel, J. U. H., Logan, B. a., Jiang, J., \& Vierling, L. A. (2014). Assessing leaf photoprotective mechanisms using terrestrial lidar: Towards mapping canopy photosynthetic performance in three dimensions. New Phytologist, 201(1), 344-356. doi:10.1111/nph.12453

Nguy-Robertson, A. L., Peng, Y., Gitelson, A. a., Arkebauer, T. J., Pimstein, A., Herrmann, I., ... Bonfil, D. J. (2014). Estimating green LAI in four crops: Potential of determining optimal spectral bands for a universal algorithm. Agricultural and Forest Meteorology, 192-193(September), 140-148. doi:10.1016/j.agrformet.2014.03.004 
684

Pittman, J., Arnall, D., Interrante, S., Moffet, C., \& Butler, T. (2015). Estimation of Biomass and Canopy Height in Bermudagrass, Alfalfa, and Wheat Using Ultrasonic, Laser, and Spectral Sensors. Sensors, 15(2), 2920-2943. doi:10.3390/s150202920

Poorter, H., Niklas, K. J., Reich, P. B., Oleksyn, J., Poot, P., \& Mommer, L. (2012). Biomass allocation to leaves, stems and roots: Meta-analyses of interspecific variation and environmental control. New Phytologist, 193(1), 30-50. doi:10.1111/j.1469-8137.2011.03952.x

Portillo-Quintero, C., Sanchez-Azofeifa, A., \& Culvenor, D. (2014). Using VEGNET In-Situ monitoring lidar (IML) to capture dynamics of plant area index, structure and phenology in Aspen Parkland Forests in Alberta, Canada. Forests, 5(5), 1053-1068. doi:10.3390/f5051053

Tavakoli, H., Mohtasebi, S. S., Alimardani, R., \& Gebbers, R. (2014). Evaluation of Different Sensing Approaches Concerning To Nondestructive Estimation of Leaf Area Index ( Lai ) for Winter Wheat, 7(1), 337-359.

Tilly, N., Hoffmeister, D., Cao, Q., Lenz-Wiedemann, V., Miao, Y., \& Bareth, G. (2015). Transferability of Models for Estimating Paddy Rice Biomass from Spatial Plant Height Data. Agriculture, 5(3), 538-560. doi:10.3390/agriculture5030538

Torino, M., Ortiz, B., Balkcom, K. S., Fulton, J., \& Wood, C. W. (2012). Evaluation of vegetation indices (VI) for their sensitivity to corn biomass and chlorophyll content changes associated with nitrogen fertilization. In ASA-CSSA-SSSA Annual Meeting Abstracts.

Tucker, C. J. (1979). Red and photographic infrared linear combinations for monitoring vegetation. Remote Sensing of Environment, 8, 127-150.

Tuley, J., Vandapel, N., \& Hebert, M. (2005). Analysis and Removal of artifacts in 3-D LADAR Data. 
Robotics Institute, (Paper 338). Retrieved from

http://ieeexplore.ieee.org/xpls/abs_all.jsp?arnumber=1570440

Ustin, S. L., Jacquemoud, S., \& Asner, G. P. (2004). Remote Sensing of the Environment: State of the Science and New Directions. In Manual of Remote Sensing (pp. 679-729).

Van Gnechten, B., Caner, H., Heine, E., García, J. L. L., Poelman, R., \& Quintero, M. S. (2008). Theory and practice on Terrestrial Laser Scanning.

Verhoef, W. (1984). Light scattering by leaf layers with application to canopy reflectance modeling: the SAIL model. Remote Sensing of Environment, 16, 125-141.

Verstraete, M. (1996). Potential and limitations of information extraction on the terrestrial biosphere from satellite remote sensing. Remote Sensing of Environment, 58(2), 201-214. doi:10.1016/S00344257(96)00069-7

Viña, A., \& Gitelson, A. A. (2005). New developments in the remote estimation of the fraction of absorbed photosynthetically active radiation in crops. Geophysical Research Letters, 32(17). doi:10.1029/2005GL023647

Vuolo, F., Neugebauer, N., Bolognesi, S. F., Atzberger, C., \& D’Urso, G. (2013). Estimation of leaf area index using DEIMOS-1 data: Application and transferability of a semi-empirical relationship between two agricultural areas. Remote Sensing, 5(3), 1274-1291. doi:10.3390/rs5031274

Wallace, L., Lucieer, A., Watson, C., \& Turner, D. (2012). Development of a UAV-lidar system with application to forest inventory. Remote Sensing, 4, 1519-1543. doi:10.3390/rs4061519

Zadoks, J.C., Chang, T.T., Zonzak, C.F., 1974. A decimal code for the growth stages of cereals. Weed 
Res. $14,415-421$.

730

731 Zarco-Tejada, P. J., Miller, J. R., Noland, T. L., Mohammed, G. H., \& Sampson, P. H. (2001). Scaling-up 732 and model inversion methods with narrowband optical indices for chlorophyll content estimation in 733 734 735

Zheng, G., \& Moskal, L. M. (2012). Computational-geometry-based retrieval of effective leaf area index

737 using terrestrial laser scanning. Geoscience and Remote Sensing, IEEE Transactions on, 50(10), $3958-3969$.

738

739

740

741

742

743

744

745

746

747

748 


\section{Figure captions:}

752 Figure 1. Autonomously operating terrestrial laser scanner (ATLS) mounted on a tower structure. For 753 more details on the design of the ATLS, please refer to Eitel et al. (2013).

754 Figure 2. Illustration of hypertemporal lidar data from an autonomously operating terrestrial laser 755 scanner (ATLS) for studying crop growth dynamics at very high spatial and temporal resolution. Figure 756 2A shows an example of an ATLS point cloud, Figure 2B shows a cross section of the wheat canopy at 757 location 1 (see Figure 2A for location labels) acquired during Julian day 150, Julian day 171, and Julian 758 day 190 and Figure $2 \mathrm{C}$ shows the wheat canopy height changes derived from ATLS data throughout the 759 growing season at location 1, 2, and 3 (see Figure 2A for location labels).

760 Figure 3. Autonomously operating terrestrial laser scanner (ATLS) derived crop height estimates within 761 the geographic footprint of RapidEye satellite pixels (pixels are shown as squares) defined by their center 762 coordinate and extent (5x5 meters).

763 Figure 4. Relationships between A) crop dry weight and measured crop height, B) measured crop height 764 and autonomously operating terrestrial laser scanner (ATLS) derived crop height, C) crop dry weight and 765 ATLS derived crop height, and D) crop dry weight and leaf area index.

766 Figure 5. Search radii for fitting the digital terrain model (lower search radius) and digital surface model 767 (upper search radius) and resulting coefficient of determination $\left(\mathrm{r}^{2}\right)$ for the regression model fit between 768 the observed crop dry weight and autonomously operating terrestrial laser scanner (ATLS) derived crop 769 height. 
770 Figure 6. Relationships between autonomously operating terrestrial laser scanner (ATLS) derived crop

771 height and spectral vegetation indices during the jointing (Zadoks 37; June 15, 2013) and heading

772 (Zadoks 50; June 29, 2013) growth stage.

773 Figure 7. True color RapidEye image of a commercial dryland wheat field near Moscow, Idaho acquired

774 on June 29, 2013 during the heading (Zadoks 50) growth stage of soft white spring wheat and associated

775 crop biomass estimates calibrated with ATLS data (biomass error is $697.50 \mathrm{~kg} \mathrm{ha}^{-1}$ (RMSE)).

776 